\title{
Living dangerously on borrowed time during slow, unrecognized regime shifts
}

\author{
Terry P. Hughes ${ }^{1}$, Cristina Linares ${ }^{2}$, Vasilis Dakos ${ }^{3,4}$, Ingrid A. van de Leemput ${ }^{3}$, and \\ Egbert H. van Nes ${ }^{3}$
}

${ }^{1}$ Australian Research Council Centre of Excellence for Coral Reef Studies, James Cook University, Townsville, QLD 4811, Australia
2 Department of Ecology, University of Barcelona, Diagonal 645, E-08028 Barcelona, Spain
${ }^{3}$ Aquatic Ecology and Water Quality Management, Wageningen University, P.O. Box 47, 6700 AA Wageningen, The Netherlands
${ }^{4}$ Integrative Ecology Group, Estación Biológica de Doñana, CSIC, Calle Américo Vespucio s/n, E-41092 Sevilla, Spain

Regime shifts from one ecological state to another are often portrayed as sudden, dramatic, and difficult to reverse. Yet many regime shifts unfold slowly and imperceptibly after a tipping point has been exceeded, especially at regional and global scales. These long, smooth transitions between equilibrium states are easy to miss, ignore, or deny, confounding management and governance. However, slow responses by ecosystems after transgressing a dangerous threshold also affords borrowed time - a window of opportunity to return to safer conditions before the new state eventually locks in and equilibrates. In this context, the most important challenge is a social one: convincing enough people to confront business-as-usual before time runs out to reverse unwanted regime shifts even after they have already begun.

\section{Transient dynamics and regime shifts}

The French Revolution, the Wall Street Crash, and the collapse of a coral reef are all examples of complex systems that exhibit threshold dynamics between alternate regimes or states. Many ecosystems exhibit such threshold responses to gradually increasing temperatures, overharvesting, or pollution, and move towards a new equilibrium state when a critical threshold or tipping point is exceeded [1,2]. The response of an ecosystem to a reversal of these drivers depends on whether there are feedbacks that reinforce and stabilize alternate states, for example, $[3,4]$. In ecology, regime shifts between alternate states are often considered to be synonymous with sudden flips or abrupt ecological surprises. Consequently, most of the ecological literature on regime shifts assumes that thresholds or tipping points are easily recognized once they have been surpassed, because an unstoppable and rapid transition to an alternate state will immediately ensue.

Here, we argue that, contrary to conventional wisdom, transitions between ecological regimes often unfold over decades, centuries, or longer, with major consequences for our capacity to detect, avoid or reverse them. These

Corresponding author: Hughes, T.P. (terry.hughes@jcu.edu.au).

Keywords: thresholds; alternate stable states; regime shift; slow responses; transient dynamics; borrowed time; climate change; resilience. transitions represent more typical 'flips' or 'surprises' that unfold in slow motion, and that take even longer to reverse. We show that the distinction between fast and slow regime shifts is important, because a rapid degradation of an ecosystem might elicit a timely management response, whereas a gradual regime shift is much more likely to go unnoticed or be ignored. We propose that the protracted transient period of a slow system supports the concept of living on borrowed time, a critical window of time when regime shifts might be reversed to prevent the new alternate state from fully eventuating, facilitating a return to the original state.

In a slowly unfolding regime shift, transient or nonequilibrium behaviour is by definition long-lasting, and might dominate for many human generations $[5,6]$. We surmise that one impediment to a clearer understanding of slow regime shifts is the emphasis in ecological theory on the asymptotic behaviour of models, where transient dynamics are typically dismissed as being short and inconsequential [3,7]. But even asymptotic behaviour of real systems is almost never static, for example, dynamic behaviour continues close to equilibrium due to stochastic variation or the influence of more complex attractors such as stable limit cycles or chaos. For some phenomena, such as disease outbreaks, the expansion of geographic ranges of invasive species, the tempo of extinction and speciation, or the eruption of social unrest in human societies, the transient dynamics are arguably the most important [8-11] and so should receive much greater attention.

One of the best studied slow, transient responses by ecosystems is succession by an assemblage of species following a disturbance. This dynamic represents a gradual return to the same equilibrium following a sudden displacement, for example, of a forest due to a fire or hurricane. The timeline from such a disturbance event to full recovery is typically several to many decades in duration. In comparison, we argue that a regime shift from one equilibrium to another (e.g., from a forest to a grassland) might be even more protracted, contrary to the commonly held assumption that regime-shifts between states are fast, while succession within one state is usually slow. Most research on ecological regime-shifts and alternate 


\section{Box 1. Slow regime shifts and management intervention}

To explore further the concept of living on borrowed time, we examine transient dynamics of a fast- versus slow-responding ecosystem to two different management interventions that both reduced the slow driver by a sufficient amount to trigger a reverse regime shift (Figure I). In the first scenario, the management intervention is delayed. Consequently, both the fast and slow system initially collapsed and equilibrated at their new alternate stable state (Figure la). The fast system abruptly switched back again when the drivers were reduced, while the slow system exhibited a much longer transient period back to the original state. In the second scenario, the management intervention occurs earlier. Only an instantaneous reaction could prevent a fast-acting system from collapsing once it passes a tipping point, for example, $[16,52]$. By contrast, the slow system avoids the full collapse, even though it too has spent a long period in the early phases of transitioning to a new regime (Figure $\mathrm{lb}$ ), and it gradually recovers to the original state. Counter-intuitively, the slow system began to respond sooner to small reversals in the driver, that were insufficient to elicit an early recovery of the collapsed fast system (Figure Ib).
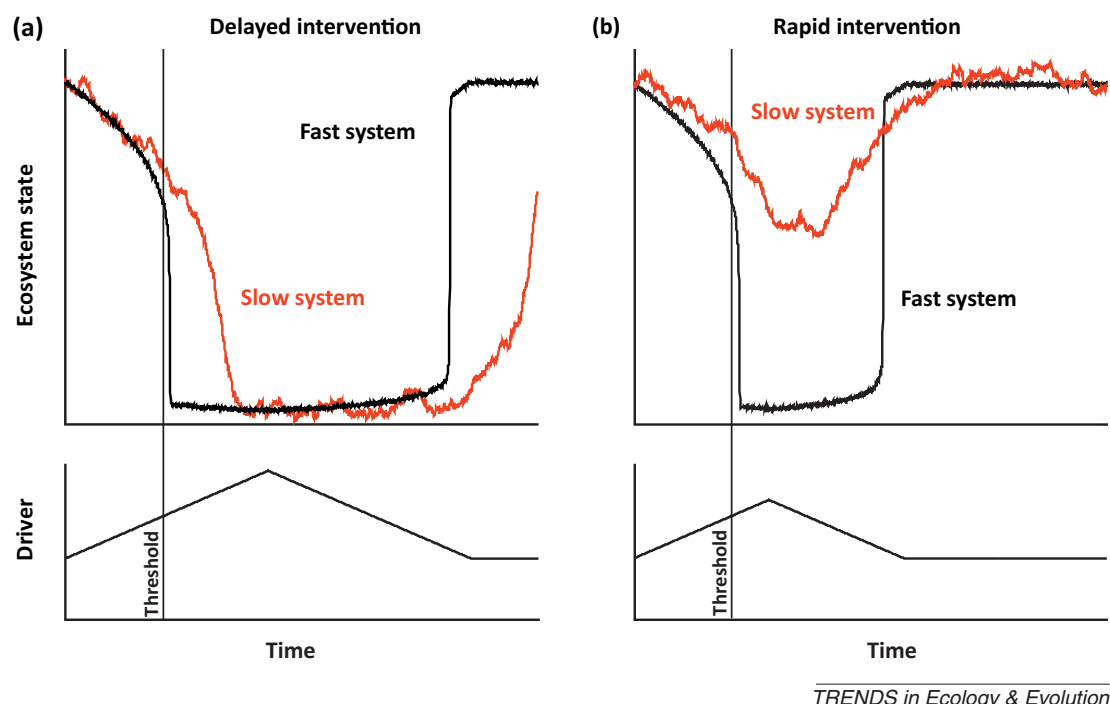

Figure I. The modelled response of fast and slow systems to (a) delayed and (b) rapid management interventions (reversal of drivers) following the transgression of a threshold separating two alternate stable states. As the environmental driver increases, it exceeds a threshold, causing a regime shift to unfold. When the driver is reversed, a second lower threshold must be crossed to induce a reversed regime shift. Note that the slow system lives on borrowed time before it eventually collapses to a new equilibrium, creating opportunities to reverse unwanted regime shifts. (See Supplemental Material for model details.)

stable states has been performed in highly dynamic systems such as small temperate lakes and ponds, which switch quickly between clear and turbid states that are characterized by different configurations of species. The transition time of a small lake after a threshold has been crossed is generally only a few months, making them ideal for experiments and model testing, for example, [12-14]. Several recent studies have focused on the search for early warning signals to predict the approach to tipping points [15-19], with the inference that ecosystems will quickly collapse afterwards to a new equilibrium - if the collapse is inevitable, every effort must be made to anticipate and avoid crossing the threshold. However, we argue below that for systems that respond much more gradually than small lakes after transgressing a threshold, the challenge of identifying and avoiding tipping points is even greater, that is, ascertaining whether we have already crossed a threshold, are now living on borrowed time, and are shifting inexorably to a new regime (Box 1).

\section{Transient responses during regime shifts}

Here we briefly review key aspects of the theory of transient behaviour between alternate states, to clarify some of important features of regime shifts. Ecosystems exhibit fundamentally different responses to gradual increases in chronic, slow drivers such as climate change [20]. The response (at equilibrium) can be incremental or 'smooth' as drivers increase, and reversible along the same trajectory if the drivers decrease (Figure 1a). Alternatively, there might be a threshold response, which is also easily reversible (Figure 1b). A third response is more difficult to reverse because reinforcing feedbacks stabilize two alternate stable states, generating a forward and backward threshold (Figure 1c). Thus, all three responses represent shifts to a new state, but only the last exhibits alternate stable states over the same intermediate range of conditions. The reversibility of regime shifts and the strength and influence of reinforcing feedbacks are poorly understood, in part because most ecological systems are under sustained human pressure, and there have been few attempts to reduce levels of drivers at meaningful scales, for example, [4,21,22].

Unfortunately, graphs like Figure $1(\mathrm{a}-\mathrm{c})$ have been widely misread in the recent ecological literature, because the $x$-axis, the driver, is commonly mistaken for time and the word 'equilibrium' is often dropped off the y-axis. In fact, every point along these curves is at equilibrium. There is no indication in this figure of time - how quickly the driver is changing, or of how long it takes for an ecosystem to reach a new equilibrium in response to a small or large change in driver. Yet, these three equilibrial responses by ecosystems are often described incorrectly as being gradual, sudden, and catastrophic (i.e., really sudden, and difficult to reverse), respectively. In reality, the pace of 


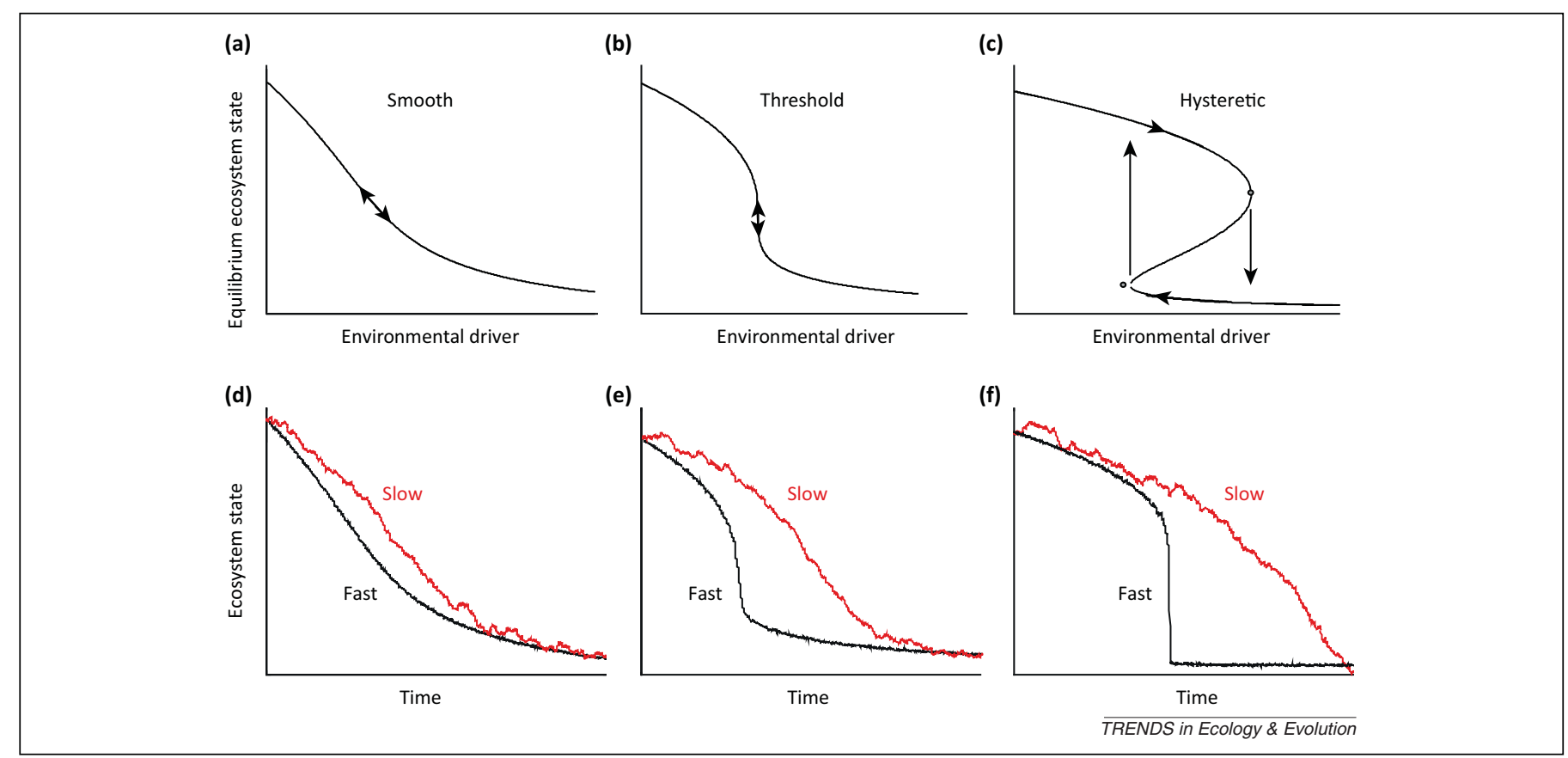

Figure 1. The response of a dynamic system (at equilibrium) to slowly changing conditions or environmental drivers might be (a) smooth, (b) a pronounced threshold at particular conditions, or (c) a transition between two alternate stable states, showing two thresholds as the driver increases or decreases. In some cases, ecosystem changes such as desertification or salinization of soils might be irreversible. This represents a fourth response (not shown), where the return trajectory intercepts the $y$-axis [53]. Many studies tacitly assume that (a) is gradual, while (b) and (c) are abrupt, even though the x-axis is not time. Moreover, the ecological behaviours in panels (a-c) are all equilibrium responses, and consequently the timeline for transition to equilibrium for any incremental increase or decrease of the drivers is undefined across its full range. In panels (d-f), we examine how fast- and slow-responding systems change through time when they respond to an escalating driver according to the smooth or abrupt equilibrial behaviour shown in (a-c). Model simulations show that fast-responding systems exhibit gradual trajectories through time (d) when the response is smooth (a), or they show abrupt trajectories through time $(e, f)$ when the response has a threshold $(b, c)$. Importantly, slowly responding systems always exhibit a gradual shift in ecosystem state through time (d-f) even after a steep threshold has been transgressed (e, f). (See Supplemental Material for model details.)

response by ecosystems to a change in conditions or drivers might be fast or slow in all three cases depending on the response time of the system.

Intuitively, fast-responding systems exhibit gradual transitions over time only when the equilibrium response to increased drivers is smooth (Figure 1d), and they show abrupt behaviour when the equilibrium response has a threshold (Figure 1e,f). By contrast, slowly responding systems always show a gradual shift to a new state even if an 'abrupt' or 'catastrophic' threshold has been transgressed (Figure 1d-f). This transient behaviour by relatively slow systems is unlikely to be recognized as a regime shift to a new equilibrium, because of the common expectation that regime shifts are necessarily sudden, unfolding over weeks or months rather than centuries or millennia. Furthermore, the time it takes to reverse a regime shift is likely to be even slower and harder to measure [21]. For example, populations of long-lived megafauna or trees might be depleted quickly by a small increase in the rate of harvesting, but their life-histories dictate very slow recoveries even if harvesting ceases completely. These slow ecosystem responses affect the dynamics and reversibility of alternate stable states, and significantly hinder the policy and management responses to crossing dangerous tipping points (Box 1).

\section{Empirical evidence for slow regime shifts}

Complex systems such as the earth's climatic, ecosystems, and societies (and combinations of them) all have elements that operate at multiple temporal and spatial scales, and these asynchronous dynamics often create complicated transient behaviour during regime shifts. For example, the time it takes for a species' range to expand or contract due to climate change varies enormously, depending on its physiology, mobility, life history, and interactions with other species [23]. Consequently, the rapid shift in climate at the end of the last ice age precipitated a succession of staggered poleward expansions of animal and plant species [24]. The northern range of maple trees expanded relatively quickly from Florida towards southern Canada between 14000 and 6000 years BP. By contrast, hemlock, beech, and chestnut took thousands of years longer to reach new northern limits, creating non-equilibrium forest assemblages that continued to change for millennia. This kind of dynamic is well-known [23], but it is rarely viewed as a slow continental-scale regime shift from one equilibrium towards another $[5,6]$. The ecosystem responses by plant assemblages to changes in climate during the Holocene continued long after the climatic drivers changed to warmer conditions, with asynchronous responses by different species over hundreds of human generations. Contemporary ecosystems across the world are also displaying this transient behaviour in response to anthropogenic climate change, creating novel assemblage structures that will continue to change for the foreseeable future, for example, $[25,26]$.

The ubiquitous phenomenon of delays between cause and effect, and its consequences for generating transient behaviour, has been explored in many contexts in population biology, community ecology, and evolution (e.g., [10,27-30]), but the connection to tipping points and alternate stable states has rarely been made explicitly. 
Time-delayed extinction is one phenomenon that generates asynchrony among species, creating transient dynamics that slow down a regime shift to a new equilibrium for decades after a threshold has been crossed. The concept of extinction debt describes the eventual extinction of longlived species after the last individual dies, following habitat loss and fragmentation [31,32]. Similarly, the theory of minimum viable population size also focuses on timedelayed extinctions [33]. Species with long generation times are most likely to have an extinction debt or to survive at low densities for multiple decades. Optimistically, this lagged response could also potentially help to buffer species losses if habitat degradation is reversed quickly enough [34,35]. Again, these forward and backward shifts in species composition have rarely been considered as representing the transient dynamics of potentially reversible regime-shifts. Importantly, transient responses during a slowly unwinding regime shift obscure historical baselines and conceal the link between cause and effect, hindering management interventions (Box 2).

\section{Climate change and regime shifts}

Shifts in climate are arguably the most pervasive slow drivers of ecological change and regime shifts, for example, [36-38]. The Arctic sea-ice is one element of the earth's climate system that exhibits threshold dynamics, where a future switch to a new equilibrium now seems inevitable [39]. Positive albedo-feedbacks in energy-balance models of this system predict two alternate states, either a stable amount of ice and snow cover, or ice-free conditions (initially during summer, but a year-round shift could occur under future climate change scenarios). Reflective snow and ice encourages one stable alternative, while heat absorption by open water reinforces the other. For

\section{Box 2. Slow transitions and shifting baselines}

Many Caribbean coral reefs began edging away from a coraldominated state in the last century, when overfishing and localized pollution first began to exceed the threshold levels required for long-term stability [54]. More recently, the impacts of climate change, emergent disease, and invasive species have also gradually escalated. Episodic mortality events (e.g., from hurricanes, coral bleaching, and disease outbreaks) and declining coral recruitment have nudged reefs incrementally away from coral dominance over multiple decades. Coral cover in the Caribbean has fallen slowly over the past $25-30$ years from an average of roughly $50 \%$ to only $10 \%$ (Figure I), while macroalgal cover has increased from 2 to $40 \%$, for example, $[49,55,56]$.

A lack of awareness of this long history of change has led some researchers to focus on recent events or current conditions as the sole or major cause of the emergence of an alternate macroalgal state $[57,58]$. A more parsimonious interpretation is that we are now witnessing the tail-end of a much longer transition (Figure I), caused by slow shifts in conditions (e.g., fishing pressure, nutrients, and climate change), as well as multiple shocks (e.g., recurrent hurricanes, mass-mortality of sea urchins in 1983, and widespread bleaching in 1995), and finally by present events and conditions. Regime shifts are commonly attributed solely to the most recent abrupt disturbance that preceded a collapse. However, acute shocks only represent the proverbial straw that breaks the camel's back, because it is the combined effects of these disturbances and slowly changing drivers that eventually trigger a regime shift towards a new stable state $[4,59]$.
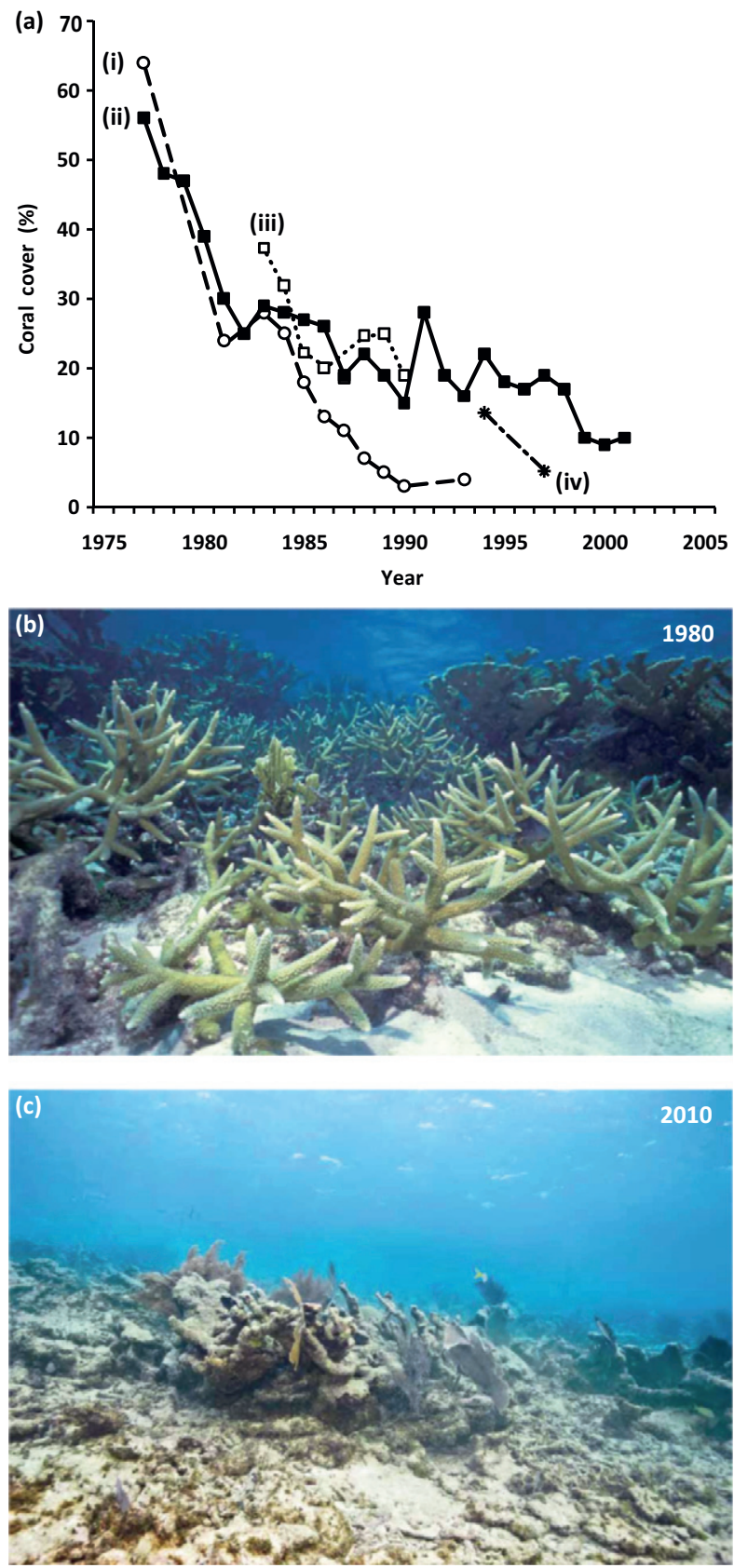

TRENDS in Ecology \& Evolution

Figure I. (a) Slow transitions in coral cover in the Caribbean over the past 25-30 years. Trajectories from (i) Jamaica [60]; (ii) a Caribbean-scale metaanalysis [55]; (iii) Panama [61]; and (iv) the Bahamas [57]. (b and c) A before and after set of photographs from the same location on South Carysford Reef, Florida taken in 1980 and 2010. The dominant species in 1980 were the staghorn coral, Acropora cervicornis, and the elkhorn coral, Acropora palmata. By 2010, the same location was mostly coral rubble, with seaweed and a few soft corals. (Reproduced, with permission from, David Arnold, www.doublexposure.net.)

ice-dependent marine mammals and the people who depend on them, the depletion of ice represents a slow regime shift with a transition phase of multiple decades [40].

An even longer timeframe is involved in the unfolding dynamic of ocean acidification and its impacts on marine ecosystems. To date, roughly one-third of anthropogenic $\mathrm{CO}_{2}$ emissions have dissolved in the surface waters of the ocean, reducing oceanic $\mathrm{pH}$ by 0.1 units since the beginning of the industrial age. The impact of this slow driver on 
marine ecosystems is lagged by different timescales depending on latitude and depth. At high latitudes, where pre-industrial carbonate concentrations in the ocean were barely above saturation, major disruption of calcifying organisms in planktonic foodwebs are forecast in the next few decades [41]. This slow regime shift represents the inevitable consequences of transgressing a threshold in atmospheric $\mathrm{CO}_{2}$ that is sufficient to cause long-term changes in polar ecosystems. At lower latitudes, serious impacts to corals and other calcifying organisms on tropical reefs could occur late this century, whereas the uptake of unabated atmospheric emissions into the deep ocean would take up to 2-3 millennia to fully unfold [42]. Once these and other marine systems have been altered by ocean acidification, they are likely to stay in a new regime for geological timescales, pointing to the imperative of action to reduce $\mathrm{CO}_{2}$ emissions as early as possible during the current transitional period [43,44].

On land, a combination of changes in climate and in land-use could also push vulnerable ecosystems beyond critical thresholds, and entrain a slow regime shift to a new stable state in both climate and ecosystems at regional scales. For example, the vegetation of the Amazon Basin contributes to the high rainfall of the region, creating a reinforcing feedback to the climate regime that is being weakened by ongoing deforestation. Lower rainfall and shorter wet seasons associated with changing ENSO oscillations, along with land clearing and habitat fragmentation that results in higher temperatures and more frequent fires, are all likely to reinforce a shift to sharply diminished forest cover and to a new climate regime over the next century [45].

\section{Living on borrowed time}

The earth has undergone many global-scale transitions in the geological past that are increasingly recognized as regime shifts $[5,6,8]$. For example, the Cambrian radiation was initiated by reaching a threshold in atmospheric oxygen, and the transition from microbes to many new phyla unfolded over a period of approximately 30 million years. The subsequent five largest mass extinctions initiated transitions to new, relatively stable states that each took hundreds of thousands to millions of years to equilibrate [46]. Today, we might surmise that human activities are already slowly pushing many ecological and earth systems closer to regional- and planetary-scale thresholds. Rockström et al. [43] developed the concept of establishing planetary boundaries for maintaining a safe distance from dangerous thresholds, to avoid entering alternate states that could reduce human wellbeing. In most cases, the existence and placement of regional and global-scale thresholds is uncertain, and it is feasible that some global or regional thresholds have already been crossed. Nevertheless, delayed responses displayed by slow systems might provide an important window of opportunity to navigate to a safer state (Box 1). A critical question is how far and for how long can a slow system transgress a threshold before the long-term transition to a new state becomes locked-in? Because of our preoccupation with equilibrium endpoints [3], the reversibility of slow regime shifts is very poorly understood for most ecosystems, and there is great uncertainty over how long a threshold might be transgressed, or by how much, before a new ecosystem state is reinforced by positive feedbacks. In the social science literature, the length of time taken to respond to disasters is increasingly recognized as a critical aspect of societal resilience to shocks such as Hurricane Katrina [47]. However, this idea has scarcely been explored by ecologists, for example, [48].

Transient phases could conceivably be the most prevalent condition in ecosystems that respond very slowly during regime shifts, or where drivers of change, such as climate, reverse cyclically. Nonetheless, most people assume that the time-scale for the change between states is far shorter than the time spent at alternate equilibria, and that transients are uncommon. For example, researchers have sought to measure the prevalence of regime shifts on coral reefs by examining the frequency distribution of states from many locations, with the expectation that regime shifts would be revealed by two distinct clusters representing alternate equilibria [49]. However, the utility of this approach is undermined by transient dynamics, because the underlying assumption that all regime shifts are abrupt is false. Asynchrony in the timing of regime shifts, different transitionary pathways, and differences in equilibrium species composition among locations will also blur the distinctiveness of alternate states at a regional scale.

In conclusion, our overview of regime shift theory and of scattered empirical evidence on slow transitions between states, for example, [6,8,10,21,29,31-33,37-39], suggests that large-scale regime shifts are often smooth and slow, generating a gradual trajectory of change that is easy to miss, deny, or ignore (Box 1). This phenomenon is likely to be widespread, and urgently requires more research (Box 3 ). The gradual approach to a threshold often goes unnoticed because of inadequate monitoring, and because there are often short-term societal benefits of approaching

\section{Box 3. Questions for future research}

\section{Modelling}

- How can we improve the analysis of non-equilibrium dynamics in models?

- What model behaviours are exhibited by coupled climateecological models, when one or both component has a threshold dynamic?

- How long can a threshold be exceeded before a long-term transition becomes irreversible?

Population biology and community ecology

- How do extinction debt and storage effects contribute to slow regime shifts?

- Under what circumstances can reversal of habitat loss prevent species extinction and avert a regime shift?

- What processes strengthen or weaken reinforcing feedbacks in ecosystems, affecting the reversibility of regime shifts?

\section{Monitoring and management}

- How can monitoring be improved to understand ecosystem dynamics and regime shifts in slow systems?

- What indicators could be measured to detect proximity to a tipping point in slow systems?

- How can the resilience of degraded states be eroded to encourage reversed regime shifts? 
or exceeding a tipping point $[16,50]$. Failure to recognize the early phases of transition towards a new state has important implications for management; slow regime shifts provide a false sense of security, effectively concealing evidence of mismanagement and providing little warning of future declines. On the other hand, even if management action to reduce drivers only begins after a threshold has been transgressed and eventually recognized, slow regime shifts are easier to reverse before they lock-in than fast collapses (Box 1).

The human imagination is poorly equipped for dealing with distant future events that contemporary generations unconsciously discount. It is hard enough to reach a societal consensus that anthropogenic climate change is real today, let alone to convince people of the longer-term threat (from current greenhouse gas emissions) of acidification in the deep ocean in 500-2000 years from now, for example, [42]. However, as exemplified here for ecological and climatic systems, regime shifts in societal norms and attitudes can and do occur, often with beneficial outcomes [11,51]. A faster human response will reduce the long-term consequences of gradual and unforeseen shifts in environmental regimes.

\section{Acknowledgements}

We thank Nick Graham and Brian Walker for feedback and suggestions. Matt Young and Lewis Anderson provided technical assistance. This research was supported by the Australian Research Council's Centre of Excellence Program. C.L. is supported by a Ramon y Cajal Fellowship from the Spanish Government. V.D. is supported by a Rubicon Fellowship grant awarded by the Netherlands Science Organisation (NWO). I.v.d.L. is supported by Ecoshape Building with Nature. E.v.N. is supported by a European Research Council (ERC) grant.

\section{Appendix A. Supplementary data}

Supplementary data associated with this article can be found, in the online version, at http://dx.doi.org/10.1016/ j.tree.2012.08.022.

\section{References}

1 Scheffer, M. and Carpenter, S.R. (2003) Catastrophic regime shifts in ecosystems: linking theory to observation. Trends Ecol. Evol. 18, 648656

2 Andersen, T. et al. (2009) Ecological thresholds and regime shifts: approaches to identification. Trends Ecol. Evol. 24, 49-57

3 Fukami, T. and Nakajima, M. (2011) Community assembly: alternative stable states or alternative transient states? Ecol. Lett. 14, 973-984

4 Hughes, T.P.et al. (2010) Rising to the challenge of sustaining coral reef resilience. Trends Ecol. Evol. 25, 633-642

5 Willis, K.J. et al. (2010) Biodiversity baselines, thresholds and resilience: testing predictions and assumptions using paleoecological data. Trends Ecol. Evol. 25, 583-591

6 Minckley, T.A. et al. (2012) Resilience and regime change in a southern Rocky Mountain ecosystem during the past 17000 years. Ecol. Monogr. $82,49-68$

7 Zychaluk, K. et al. (2012) Data-driven models for regional coral-reef dynamics. Ecol. Lett. 15, 151-158

8 Alroy, J. (2008) Dynamics of origination and extinction in the marine fossil record. Proc. Natl. Acad. Sci. U.S.A. 105, 11536-11542

9 Daehler, C.C. (2009) Short lag times for invasive tropical plants: evidence from experimental plantings in Hawai'i. PLoS ONE 4, e4462

10 O'Dea, A. and Jackson, J. (2009) Environmental change drove macroevolution in cupuladriid bryozoans. Proc. R. Soc. B: Biol. Sci. 276, 3629-3634

11 Ayadi, R. et al. (2011) The Tunisian revolution: an opportunity for democratic transition, IAI working papers 1102. 1-6, Insituto Affari Internazionali
12 Scheffer, M. et al. (2009) Early-warning signals for critical transitions. Nature 461, 53-59

13 Carpenter, S.R. et al. (2011) Early warnings of regime shifts: a wholeecosystem experiment. Science 332, 1079-1082

14 Van Geest, G.J. et al. (2007) Long transients near the ghost of a stable state in eutrophic shallow lakes with fluctuating water levels. Ecosystems 10, 36-46

15 Dakos, V. et al. (2008) Slowing down as an early warning signal for abrupt climate change. Proc. Natl. Acad. Sci. U.S.A. 105, 14308-14312

16 Biggs, R. et al. (2009) Turning back from the brink: detecting an impending regime shift in time to avert it. Proc. Natl. Acad. Sci. U.S.A. 106, 826-831

17 Guttal, V. and Jayaprakash, C. (2009) Spatial variance and spatial skewness: leading indicators of regime shifts in spatial ecological systems. Theor. Ecol. 2, 3-12

18 Veraart, A.J. et al. (2012) Recovery rates reflect distance to a tipping point in a living system. Nature 481, 357-359

19 Carpenter, S.R. and Brock, W.A. (2011) Early warnings of unknown nonlinear shifts: a nonparametric approach. Ecology 92, 2196-2201

20 Walker, B. and Meyers, J.A. (2004) Thresholds in ecological and socialecological systems: a developing database. Ecol. Soc. 9, 3

21 Frank, K.T. et al. (2011) Transient dynamics of an altered large marine ecosystem. Nature 477, 86-89

22 Bellwood, D.R. et al. (2006) Sleeping functional group drives coral-reef recovery. Curr. Biol. 16, 2434-2439

23 Pimm, S.L. (2009) Climate disruption and biodiversity. Curr. Biol. 19, R595-R601

24 Hill, J.K. et al. (2011) Climate change and evolutionary adaptations at species' range margins. Annu. Rev. Entomol. 56, 143-159

25 Yamano, H. et al. (2011) Rapid poleward range expansion of tropical reef corals in response to rising sea surface temperatures. Geophys. Res. Lett. 38, L04601

26 Chen, I-C. et al. (2011) Rapid range shifts of species associated with high levels of climate warming. Science 333, 1024-1026

27 Farrer, E.C. et al. (2010) Time lags and the balance of positive and negative interactions in driving grassland community dynamics. Am. Nat. 175, 160-173

28 Metzger, J.P. et al. (2009) Time-lag in biological responses to landscape changes in a highly dynamic Atlantic forest region. Biol. Conserv. 142, 1166-1177

29 Altieri, A. et al. (2012) A trophic cascade triggers collapse of a saltmarsh ecosystem with intensive recreational fishing. Ecology 93, 14021410

30 Angeler, D.G. et al. (2009) Statistical performance and information content of time lag analysis and redundancy analysis in time series modeling. Ecology 90, 3245-3257

31 Kuussaari, M. et al. (2009) Extinction debt: a challenge for biodiversity conservation. Trends Ecol. Evol. 24, 564-571

32 Krauss, J. et al. (2010) Habitat fragmentation causes immediate and time-delayed biodiversity loss at different trophic levels. Ecol. Lett. 13, $597-605$

33 Bulman, C.R. et al. (2007) Minimum viable metapopulation size, extinction debt, and the conservation of a declining species. Ecol. Appl. 17, 1460-1473

34 Wright, S.J. and Muller-Landau, H.C. (2006) The future of tropical forest species. Biotropica 38, 287-301

35 Laurance, W.F. (2007) Have we overstated the tropical biodiversity crisis? Trends Ecol. Evol. 22, 65-70

36 Hughes, T.P. et al. (2003) Climate change, human impacts, and the resilience of coral reefs. Science 301, 929-933

37 Pelejero, C. et al. (2010) Paleo-perspectives on ocean acidification. Trends Ecol. Evol. 25, 332-344

38 Menendez, R. et al. (2006) Species richness changes lag behind climate change. Proc. R. Soc. B: Biol. Sci. 273, 1465-1470

39 Lenton, T.M. et al. (2008) Tipping elements in the Earth's climate system. Proc. Natl. Acad. Sci. U.S.A. 105, 1786-1793

40 Adger, W.N. et al. (2011) This must be the place: underrepresentation of identity and meaning in climate change decision-making. Global Environ. Polit. 11, 1-25

41 Yamamoto-Kawai, M. et al. (2009) Aragonite undersaturation in the Arctic Ocean: effects of ocean acidification and sea ice melt. Science 326 , 1098-1100 
42 Caldeira, K. and Wickett, M.E. (2003) Anthropogenic carbon and ocean pH. Nature 425, 365

43 Rockström, J. et al. (2009) Planetary boundaries: exploring the safe operating space for humanity. Ecol. Soc. 14, 32

44 Vaughan, N.E. et al. (2009) Climate change mitigation: trade-offs between delay and strength of action required. Clim. Change 96, 29-43

45 Malhi, Y. et al. (2008) Climate change, deforestation, and the fate of the Amazon. Science 319, 169-172

46 Barnosky, A.D. et al. (2012) Approaching a state shift in Earth's biosphere. Nature 486, 52-58

47 Walker, B. and Westley, F. (2011) Perspectives on resilience to disasters across sectors and cultures. Ecol. Soc. 16, 4

48 Tanner, J.E. et al. (1996) The role of history in community dynamics: a modelling approach. Ecology 77, 108-117

49 Bruno, J.F. et al. (2009) Assessing evidence of phase shifts from coral to macroalgal dominance on coral reefs. Ecology 90, 1478-1484

50 Steneck, R.S. et al. (2011) Creation of a gilded trap by the high economic value of the Maine lobster fishery. Conserv. Biol. 25, 904-912

51 Walker, B. et al. (2009) Looming global-scale failures and missing institutions. Science 325, 1345-1346
52 Contamin, R. and Ellison, A.M. (2009) Indicators of regime shifts in ecological systems: what do we need to know and when do we need to know it? Ecol. Appl. 19, 799-816

53 Walker, B. et al. (2010) Incorporating resilience in the assessment of inclusive wealth: an example from South East Australia. Environ. Resour. Econ. 45, 183-202

54 Pandolfi, J.M. et al. (2003) Global trajectories of the long-term decline of coral reef ecosystems. Science 301, 955-958

55 Gardner, T.A. et al. (2003) Long-term region-wide declines in Caribbean corals. Science 301, 958-960

56 Cote, I.M. et al. (2005) Measuring coral reef decline through metaanalyses. Philos. Trans. R. Soc. B: Biol. Sci. 360, 385-395

57 Ostrander, G.K. et al. (2000) Rapid transition in the structure of a coral reef community: the effects of coral bleaching and physical disturbance. Proc. Natl. Acad. Sci. U.S.A. 97, 5297-5302

58 Mora, C. (2008) A clear human footprint in the coral reefs of the Caribbean. Proc. R. Soc. B: Biol. Sci. 275, 767-773

59 Scheffer, M. et al. (2008) Pulse-driven loss of top-down control: the critical-rate hypothesis. Ecosystems 11, 226-237

60 Hughes, T.P. (1994) Catastrophes, phase-shifts, and large-scale degradation of a Caribbean coral-reef. Science 265, 1547-1551

61 Shulman, M.J. and Robertson, D.R. (1996) Changes in the coral reefs of San Blas, Caribbean Panama: 1983 to 1990. Coral Reefs 15, 231-236 